this insoluble mass. It seems to be quite insoluble in hydrochloric acid though easily dissolved by water. Analysis shows that this mass is $\mathrm{ZrOCl}_{2}$ and with it was found, as an impurity, whatever silica the separation by heating failed to remove.

Lastly, my assistant, Mr. Baskerville, has shown that much time and hydrochloric acid will be saved if, in the solutions containing much iron, the zirconium hydroxide be first precipitated out by means of sulphur dioxide. This precipitate can then be dissolved in acid and purified by crystallization as already recommended.

Of course it need scarcely be mentioned that if silica has been removed by ignition and treatment with hydrofluoric acid, it will be necessary to fuse once more with caustic alkali and repeat the ordinary purification.

UNIVERITY OF NORTH CAROIINA, April 12, I 894 .

\title{
SEPARATION OF ZIRCONIUM BY MEANS OF SULPHUROUS ACID.
}

BY CharLes BaskERVILLE. Received April 16, 1894 .

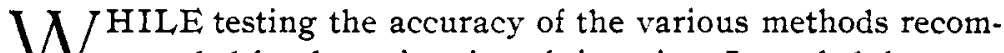
mended for the estimation of zirconium I was led, because of the analogy of the elements, to try a method commonly used with titanium; viz., prolonged boiling of a potassium bisulphate fusion in dilute solution with sulphurous acid in excess. On application of this method, however, on a solution of zirconium sulphate (prepared by dissolving the hydroxide in sulphuric acid), I failed even after boiling four hours with an excess of sulphur dioxide to obtain a precipitate, if the solution was acid. If the solution was nearly neutralized with ammonium hydroxide and then boiled with an excess of sulphur dioxide, after being greatly diluted, a precipitate was produced. This precipitation, however, was incomplete, even after boiling six hours or passing steam through the same for two or three hours. The precipitate too was very finely divided, running through all filter papers at my command. Therefore this method could not be used.

But an addition of sulphurous acid to a solution of zirconium chloride, even in a cold acid solution, a dense white precipitate was immediately noted. On boiling with an excess of sulphurous 
acid in a neutralized solution, $i . e$, the hychochloric acid solution neutralized by ammonium hydroxide until the slight precipitate formed was no longer dissolved on boiling. and this precipitate then taken up with two or three drops of dilute hydrochloric acid, the zirconium was completely precipitated.

The accuracy of the method is seen in the following results:

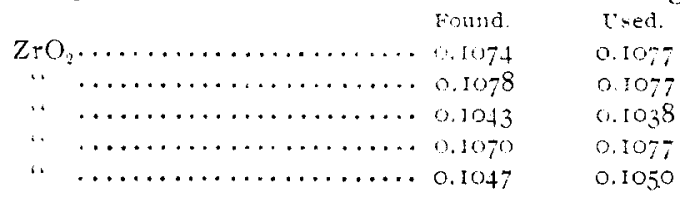

The precipitation took place immediately on addition of sulphurous acid, and after two minutes boiling the precipitate settled quickly and was easily filtered.

This method then is applicable to the chloride only, and a sulphate would have to be first changed into chloride by precipitation with ammonium hydroxide and re-solution in hydrochloric acid. The presence of large amounts of such salts as ammonium chloride did not aid the precipitation of the sulphate. The presence of free hydrochloric acid must be aroicled and it is best to use a fresh solution of sulphurous acid or the sulphur dioxide gas direct.

This method affords an excellent means of separating zirconium from iron. Several experiments were carried out upon solutions containing known amounts of the chlorides of these two metals. The zirconia was precipitated by sulphurous acid, boiled five minutes, and washed four or five times with hot water. The iron was titrated in the filtrate.

The experiments resulted as follows:

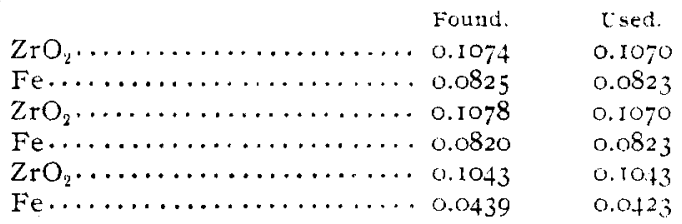

This method served for the separation of zirconium and aluminum as well, as may be seen by the following results:

$$
\text { Found. rsed. }
$$

$\mathrm{ZrO}_{2} \ldots \ldots \ldots \ldots \ldots \ldots \ldots \ldots, 0.1042 \quad 0.1043$

$\mathrm{Al}_{2} \mathrm{O}_{3} \ldots \ldots \ldots \ldots \ldots \ldots \ldots \ldots, 0.0608 \quad 0.0650$

$\mathrm{ZrO}_{2} \ldots \ldots \ldots \ldots \ldots \ldots \ldots \ldots \ldots+0.1070 \quad 0.1070$

$\mathrm{Al}_{2} \mathrm{O}_{3} \ldots \ldots \ldots \ldots \ldots \ldots \ldots \ldots .0 .316 \quad 0.0305$

VNIVERSiTY OF NORTH CAROLINA. 